\title{
Perioperative considerations in the treatment of endometriosis
}

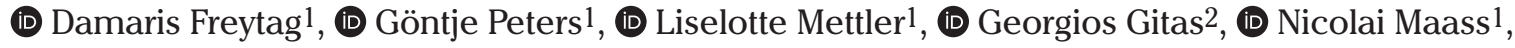 \\ (D) Ibrahim Alkatout ${ }^{1}$ \\ ${ }^{1}$ Department of Obstetrics and Gynecology, University Hospital Schleswig-Holstein, Campus Kiel, Kiel, Germany \\ 2Department of Obstetrics and Gynecology, University Hospital Schleswig-Holstein, Campus Lübeck, Lübeck, Germany
}

\section{Abstract}

Endometriosis is one of the most common benign diseases in women of reproductive age. Nearly all gynecological offices and clinics will contain patients with endometriosis; the frequency and severity of the disease will vary from one setting to another. Adjoining specialties, such as internal medicine, general medicine, surgery, urology, orthopedics, neurology and psychosomatic medicine, will be challenged directly or indirectly by various forms of endometriosis and its sequelae. The disease is characterized by pelvic pain, dysmenorrhea, dyspareunia and sterility. Even now, several years may elapse between the onset of the disease and its diagnosis. The diagnosis of endometriosis is complicated by the diversity of the symptoms. A precise documentation of the patient's medical history and thorough diagnostic procedures are essential to establish a robust diagnosis. This article will discuss the perioperative considerations, diagnosis and treatment of endometriosis. (J Turk Ger Gynecol Assoc 2021; 22: 319-25)

Keywords: Deep infiltrating endometriosis, preoperative diagnosis, transvaginal ultrasound, adenomyosis, infertility

Received: 18 January, 2021 Accepted: 29 March, 2021

\section{Introduction}

Endometriosis is one of the most common benign diseases in women of reproductive age. Non-specific symptoms, such as pain in the lower abdomen, dysmenorrhea, dyspareunia, bleeding disorders, cyclic micturition or defecation disorders, the unfulfilled desire to have children, or chronic fatigue are among the diverse pathomorphological symptoms and their location, as well as the manifold reactions of patients to the disease. Therapy options are equally diverse. These range from analgesia, watchful waiting and endocrine treatment to surgical strategies and combined procedures. The treatment should be aligned to the patient's condition (1-4). Quality of life is, in some cases, markedly impaired by endometriosis. The financial burden on health care systems and absenteeism from work are of significant socioeconomic significance. Patients with endometriosis have a diminished capacity for work: their average absence from work amounts to 7.41 hours per week (5).

Primarily due to lack of awareness of the disease, both on the part of patients and clinicians, an average period of 10.4 years elapses between the onset of non-specific symptoms and the establishment of the diagnosis. During this time, patients experience at least one erroneous diagnosis (6). As the symptoms may be quite general, false diagnoses, such as an irritable colon or pelvic inflammatory disease, are common (7). Similar numbers have been reported internationally with a mean diagnostic latency for endometriosis of 8 years in the United Kingdom and 11.7 years in the USA (8-11). In terms of pathogenesis, the disease is attributed to various factors, including retrograde menstruation, coelomic metaplasia, metastasis, altered cellular immunity, and a multifactorial mode of inheritance with interactions between the environment and specific genes (12-16). 


\section{Symptoms}

Characteristic symptoms of endometriosis include dysmenorrhea, dyspareunia, chronic pain in the lower abdomen, cyclic defecation or micturition disorders, sterility, or bleeding disorders. However, the pattern of symptoms may be quite ambiguous. Potential differential diagnoses (Table 1) must be noted and, if necessary, clarified by interdisciplinary consultation $(17,18)$.

Pain intensity in endometriosis can be quantified by the use of a visual analog scale (VAS). The severity of pain using a VAS may be rated from zero (no pain) to ten (maximum pain). In addition to the intensity of pain, the patient should be asked about the duration of impairment in daily life, expressed in numbers of days per month. However, the clinician evaluating the symptoms should keep in mind the fact that the extent of disease or the size of the lesion is not always correlated with the intensity of pain (19).

\section{Diagnosis}

The patient's detailed medical history is complemented by a careful gynecological investigation. International and national guidelines demand a structured diagnostic approach $(17,18)$. Apart from inspection and palpation of the abdomen, the vagina should be investigated with a bivalve speculum in an appropriate setting. The bivalve speculum permits the detection of deep infiltrating lesions in the posterior vaginal vault. A bimanual palpation should also be performed. After informing the patient in advance, the clinician should perform

Table 1. Differential diagnoses of acute and chronic pain in the lower abdomen in women of reproductive age (3)

\begin{tabular}{|l|l|}
\hline Gynecological causes & Non-gynecological causes \\
\hline Endometriosis & Acute or chronic appendicitis \\
\hline Regular pregnancy & Nephrolithiasis \\
\hline Intrauterine abortion & $\begin{array}{l}\text { Perforation of a hollow organ } \\
\text { (e.g. stomach, bowel, gallbladder) }\end{array}$ \\
\hline Ectopic pregnancy & Obstruction of a hollow organ \\
\hline Ovarian torsion & $\begin{array}{l}\text { Intra-abdominal inflammation } \\
\text { (peritonitis, diverticulitis, terminal ileitis, } \\
\text { cholecystitis, gallstones) }\end{array}$ \\
\hline Ovarian cyst & $\begin{array}{l}\text { Rupture of a parenchymal organ } \\
\text { (liver, spleen, kidneys) }\end{array}$ \\
\hline $\begin{array}{l}\text { Ruptured follicle or } \\
\text { corpus luteum-cyst }\end{array}$ & $\begin{array}{l}\text { Intra-abdominal infarction } \\
\text { (bowel, mesentery) }\end{array}$ \\
\hline Myoma & Internal bleeding \\
\hline Adnexitis & Cystitis/pyelonephritis \\
\hline $\begin{array}{l}\text { Benign and malignant } \\
\text { tumors of the inner } \\
\text { genital organs }\end{array}$ & $\begin{array}{l}\text { Benign and malignant tumors of the } \\
\text { gastrointestinal tract }\end{array}$ \\
\hline
\end{tabular}

a digital rectal examination, especially in cases of suspected deep infiltrating endometriosis. If possible, the surgeon himself/ herself should perform the preoperative clinical investigation, record the patient's medical history (Table 2), and inform the patient about the subsequent procedure $(3,17,18)$.

The combination of these actions is essential to obtain maximum information and minimize the risk of unexpected findings or omission of significant lesions. This approach also permits the identification of trigger points or the point of maximum pain, which yield crucial clinical data. These investigations are aided by an ultrasound investigation of the pelvic organs. In cases of suspected deep infiltrating endometriosis, an ultrasound investigation of the kidneys should be performed to rule out hydronephrosis $(17,18)$.

Transvaginal ultrasound is the preferred diagnostic imaging procedure for the detection of endometriosis. It is widely available, economical, minimally invasive, and very informative in regard to deep infiltrating endometriosis, adenomyosis, or ovarian endometriosis (20). The published literature reports a sensitivity and specificity of $85 \%$ and $100 \%$, respectively, for transvaginal ultrasound $(21,22)$. In cases of deep infiltrating endometriosis, a magnetic resonance imaging investigation may optionally be performed as an additional imaging procedure. However, both methods yield similar results (20). Potential deep infiltrating nodules in the rectovaginal or vesicovaginal aspect can even be detected by transvaginal ultrasound. In cases of pronounced adenomyosis, these nodules may spread into the transuterine aspect or, independent of such infiltration, may also spread into adjacent regions. This must be included in the preoperative spectrum of endometriosis because surgical treatment may be difficult in these cases; patients should be informed preoperatively of the fact that dysmenorrhea or bleeding disorders may persist even after surgery. Furthermore, patients who wish to have children should be informed of the fact that adenomyosis may hinder conception $(2,3)$.

\section{Table 2. Documentation of medical history in the} presence of endometriosis $(3,17,18)$

\section{Checklist-Essential questions regarding endometriosis}

Pain shortly before or during menstruation

Cyclic symptoms and/or symptoms independent of the menstrual cycle

Pain during micturition or defecation

Blood in urine or stool

Pain during sexual intercourse

Unfulfilled desire to have children

Impaired quality of life

No symptoms 
In cases of suspected deep infiltrating endometriosis and possible involvement of the bowel, a rectal endoscopic ultrasound investigation permits exact inspection and evaluation of the intestinal wall and its histological layers. This has far-reaching consequences for the treatment strategy (such as shaving versus partial bowel resection) $(2,3,23)$. The primary purpose of preoperatively determined parameters is to aid the surgeon in estimating the extent of surgery and working out an individual therapy regimen, in consultation with the patient. The therapeutic strategy should take the patient's symptoms, wishes, emotional stress levels, the presence of limited organ function, and the reproductive aspect into account. Especially in cases of suspected deep infiltrating endometriosis and depending on the nature of preoperative findings, the surgical team should include a general surgeon skilled in endoscopy and a urologist (if necessary) in addition to the gynecologist. This is best achieved by referring the patient to a certified endometriosis center with expertise and specialized skills in the treatment of the disease $(17,18)$.

\section{Endometriosis and uterine malformations}

The coexistence of endometriosis and uterine malformations, as shown in Figure 1a, b, which are frequently diagnosed during the exploration of infertility, has been reported by many authors (16,24-27). The underlying pathological mechanism could be intensified retrograde menstruation (27-29). This fact should also be included in preoperative considerations, especially in women who still desire to have children. Congenital uterine anomalies are more common than was previously assumed. Their clinical presentation depends on the anomalies and

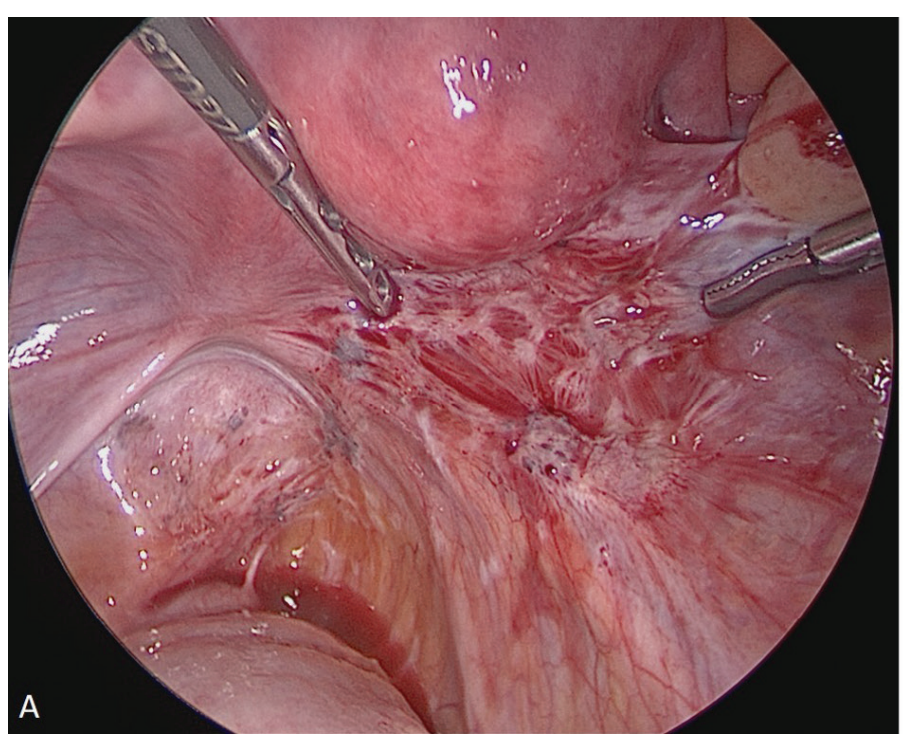

the woman's reproductive age. Some patients may be asymptomatic, with normal fertility and obstetric outcomes, while others may have primary amenorrhea, endometriosis, menstrual irregularities and infertility (16). The use of threedimensional transvaginal ultrasound is extremely useful in these cases because it permits reconstruction of the uterine cavity and assessment of the external contours of the fundus (Figure 2a, b). The septate/subseptate uterus is the most common uterine malformation and is therefore of greatest significance in women who desire to have children (Figure 3) $(16,25)$. Nawroth et al. (24), and recently LaMonica et al. (25) described a high rate of endometriosis in women with a septate uterus. Freytag et al. (16) showed that uterine malformations and adenomyosis frequently occur together, and their coexistence appears to be correlated with severe endometriosis. Therefore, endometriosis should always be suspected in patients with uterine malformations. Any surgical investigation of sterility should be performed as a combined hysteroscopy and laparoscopy (16).

\section{Transvaginal ultrasound}

In 2016, the International Deep Endometriosis Analysis group published a consensus paper with recommendations for specific diagnostic procedures in cases of suspected deep infiltrating endometriosis (30). A transvaginal ultrasound investigation is recommended in four steps of the examination procedure (30):

The first step is an evaluation of the uterus and uterine appendages. In addition to the mobility of the uterus, the myometrium should be inspected for sonographic signs of adenomyosis. The criteria specified by the Morphological

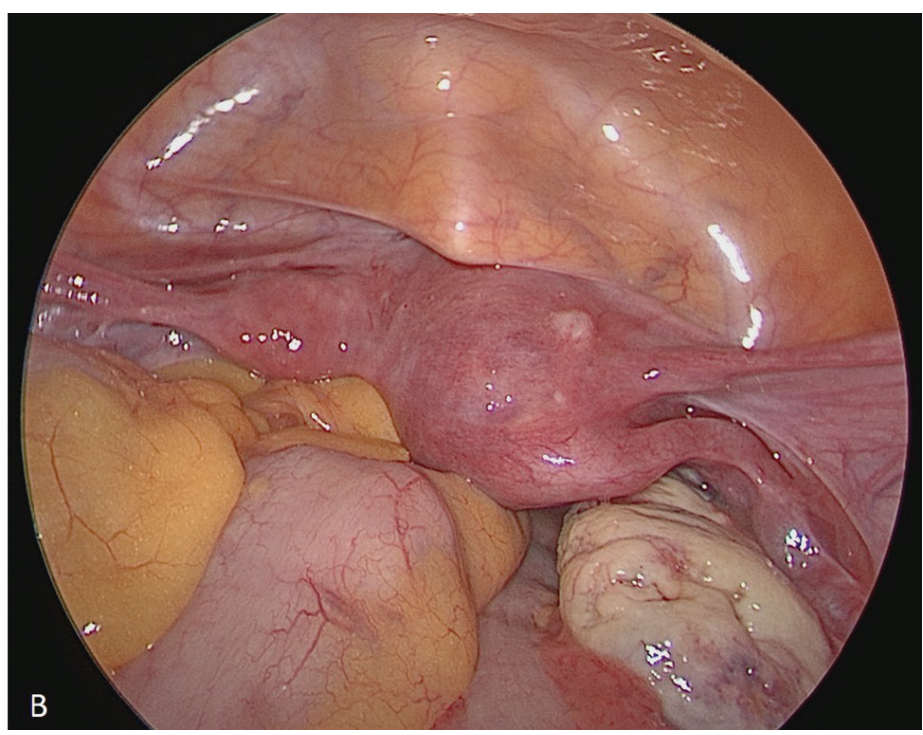

Figure 1. (A) Intraoperative findings in a 32-year-old patient with dysmenorrhea, dyspareunia and sterility. (B) In addition to deep infiltrating endometriosis, this patient has a uterine malformation by way of a unicornuate uterus with a noncommunicating horn with functional endometrium. The fallopian tubes are seen here, and ligaments are inserted in the rudimentary horn 

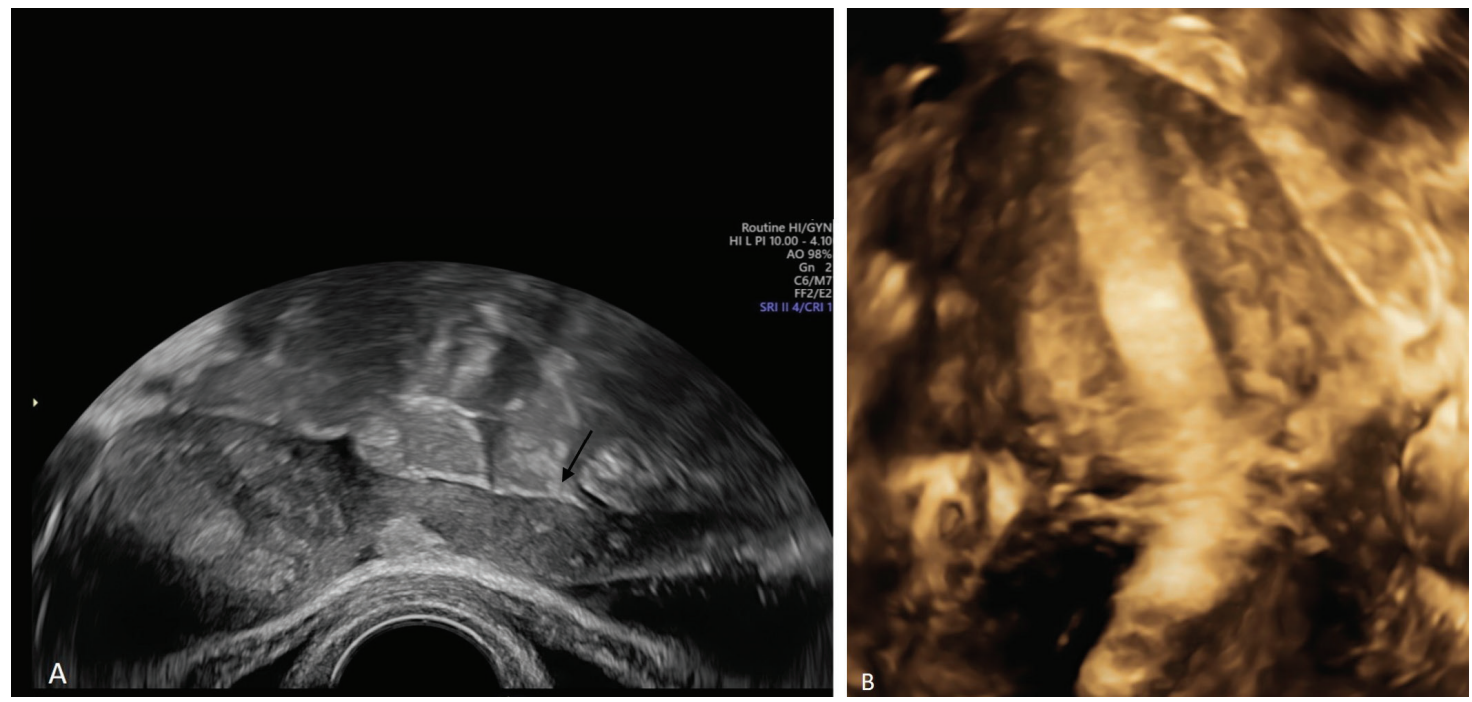

Figure 2. (A) Preoperative two-dimensional transvaginal ultrasound. The cross-section reveals a uterus deviated markedly to the left and a rudimentary horn with a small hyperechoic island of endometrial tissue. (B) Preoperative three-dimensional transvaginal ultrasound. The coronal plane reveals a markedly left-sided uterus and only one ostium of the fallopian tube and a narrow, elongated uterine cavity. The finding was confirmed on hysteroscopy. This patient has a non-communicating rudimentary horn

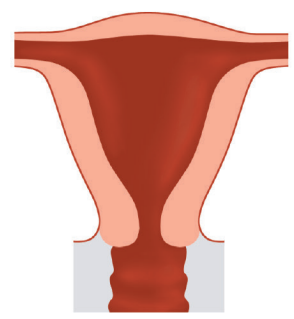

Normal

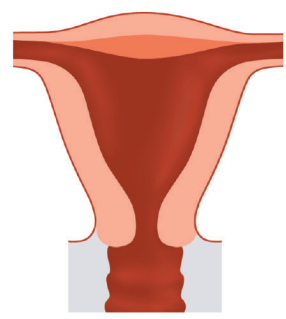

Arcuate
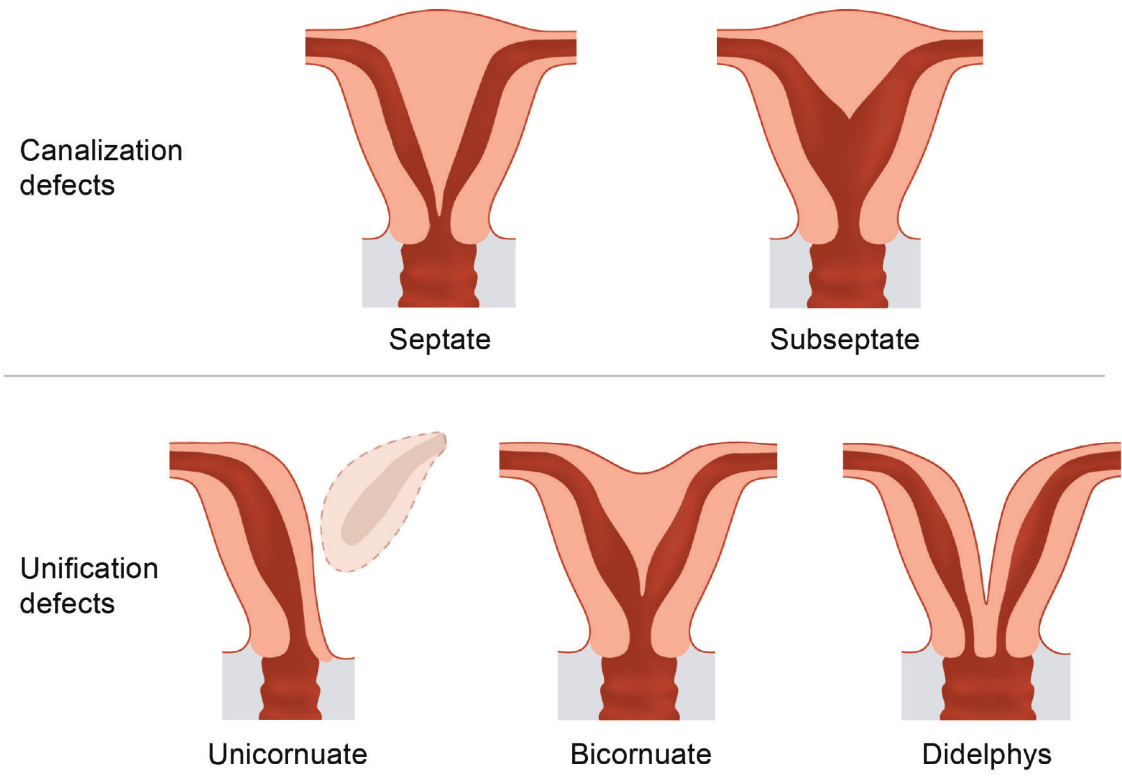

Figure 3. Schematic view of uterine malformations. The external contour of the uterus is colored orange. The uterine cavity is shown in red 
Uterus Sonographic Assessment (MUSA) group should be used to describe these signs (31). The clinician looks for endometriomas in the uterine appendages, which should be described in accordance with the criteria given in the International Ovarian Tumor Analysis terminology (32). Endometriomas are usually unilocular cysts with ground glass echogenicity (30). A typical finding on color Doppler ultrasound is no, or minimal, vascularization of the cyst wall. These are usually associated with other endometriotic lesions particularly in the fallopian tubes, extensive adhesions, and deep infiltrating endometriosis. Mutually adherent retrouterine endometriomas and adherent ovaries are also referred to as kissing ovaries (Figure 4) (33). Kissing ovaries usually occur in conjunction with deep infiltrating endometriosis (33).

So-called soft markers are assessed in the second step of the investigation (30). Is the clinician able to locate painful regions? Are the ovaries movable (30).

The third step of the investigation includes a dynamic ultrasound examination for assessment of the so-called sliding sign. When the cervix, the posterior wall of the uterus and the fundus are movable, and the rectum and sigmoid colon can glide freely across the above-mentioned structures, the sliding sign is considered positive (30).

In the fourth step of the investigation, the clinician inspects the anterior and posterior compartments of the uterus in regard to deep infiltrating endometriosis. To locate the anterior compartment, which includes the bladder, the vesico-uterine pouch and the ureters, the ultrasound probe is placed in the anterior fornix. In addition to the mobility of the bladder (vesico-uterine adhesions), the investigator looks for deep infiltrating lesions. The bladder should be slightly filled with urine (30). Endometriotic lesions of the bladder are most frequently found in the posterior wall, followed by the base of the bladder (34). Visualization of the pelvic portion of the ureters is no substitute for an ultrasound investigation of the kidneys to exclude the presence of concomitant

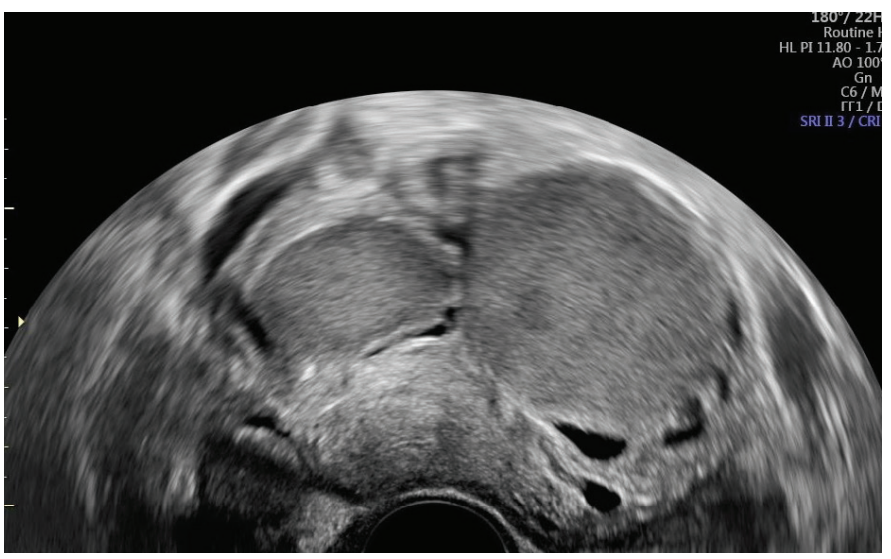

Figure 4. Ultrasound image of kissing ovaries with typical ground glass echogenicity hydronephrosis (35). The posterior compartment is examined by placing the ultrasound probe in the posterior fornix. Here the clinician will be able to evaluate the sacrouterine ligaments, the vagina, the rectovaginal septum, the anterior rectum, the rectosigmoid junction, and the sigmoid colon. It should be noted that entities, such as the sacrouterine ligaments, may be visualized on transvaginal ultrasound only in the presence of pathological conditions (30).

\section{Adenomyosis: a special condition}

Adenomyosis poses special problems for the managing physician in terms of diagnostic investigation and therapy. Patients are frequently young and still wish to have children. Therefore, hysterectomy is no option as a therapy of choice (36). Clinical symptoms of the disease include dysmenorrhea, menorrhagia, dyspareunia and pain in the lower abdomen. Furthermore, adenomyosis is a cofactor of female subfertility. The clinician must include this aspect in his/her preoperative considerations for the treatment of endometriosis, and counsel the patient accordingly (3).

A distinction is made between diffuse and focal adenomyosis. These are differentiated from adenomyomas. On histological investigation, adenomyomas are marked by additional compensatory hypertrophy of the surrounding myometrium (31). Differentiating this condition from myoma may be challenging, especially when both pathologies are present together. Color Doppler ultrasound may be useful in this setting. As mentioned earlier, the ultrasound investigation of adenomyosis should be performed in accordance with the MUSA criteria (31). Ultrasound findings (Figure 5,6) that indicate the presence of adenomyosis include an asymmetrical thickening of the wall, so-called striae-like vascular patterns, fan-shaped shadowing, myometrial cysts, hyperechoic islands, echogenic buds and strips, and an irregular or interrupted junctional zone. The latter can be visualized well with the aid of three-dimensional transvaginal ultrasound in the coronal plane (31).

\section{Conclusion}

An exact documentation of the patient's medical history and careful diagnostic investigation with the aid of transvaginal ultrasound are prerequisites for planning effective treatment in patients with endometriosis. The diagnostic investigation must be based on profound knowledge of the typical symptoms of the disease, which include dysmenorrhea, dyspareunia, chronic pain in the lower abdomen, cyclic defecation or micturition disorders, sterility, or bleeding disorders. Patients should be referred to a certified endometriosis center for diagnostic investigation and treatment. 

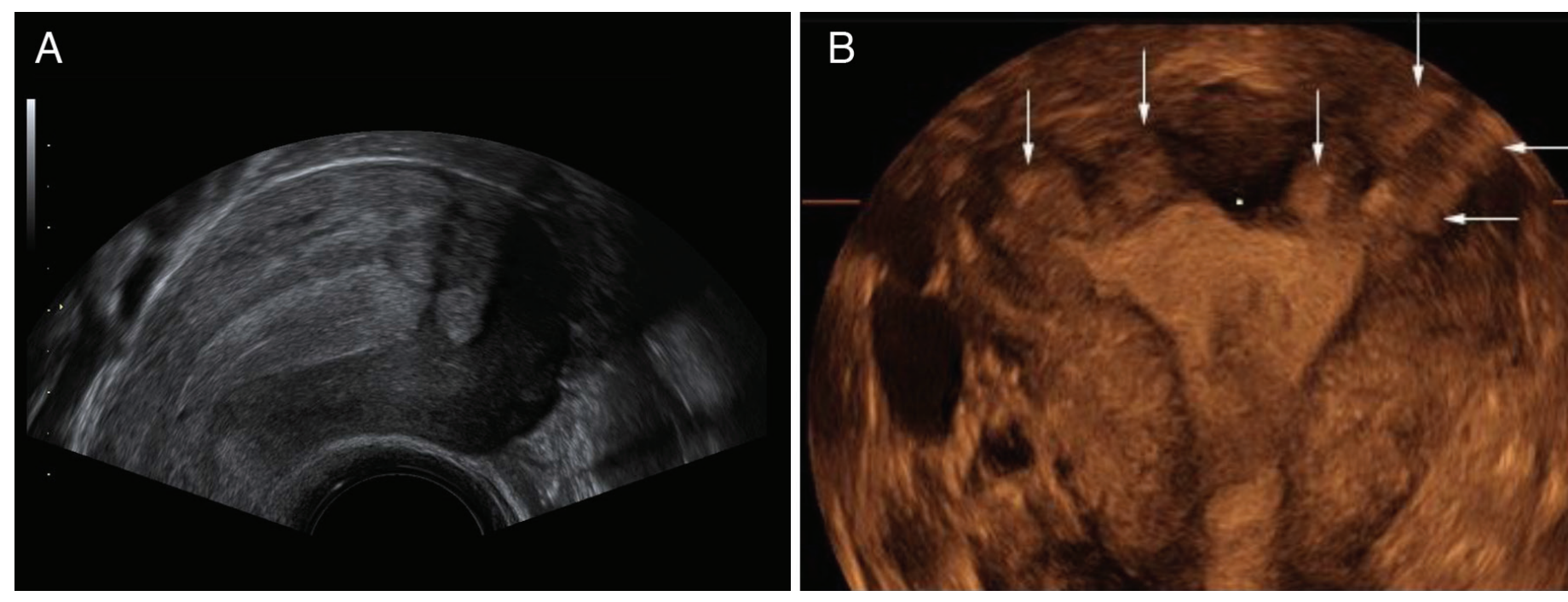

Figure 5. (A) This ultrasound image - a sagittal section through the uterus - shows adenomyotic lesions close to the endometrium. Characteristically, these lesions have the same echogenicity [extracted from (37)]. (B) In the coronal plane the three-dimensional transvaginal ultrasound investigation shows several adenomyotic lesions arising from the endometrium close to the fundus [extracted from (37)]

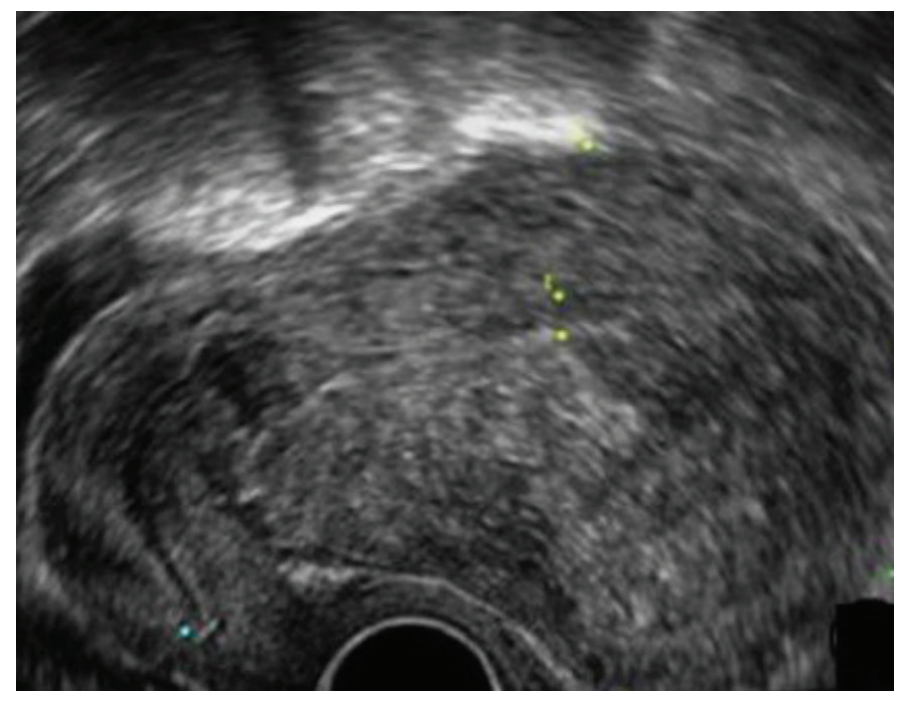

Figure 6. This sagittal section through the uterus shows the frequently encountered asymmetry of the uterine walls in the presence of adenomyosis

Peer-review: Externally peer-reviewed.

Conflict of Interest: No conflict of interest is declared by the authors.

Financial Disclosure: The authors declared that this study received no financial support.

\section{References}

1. Olive DL, Schwartz LB. Endometriosis. N Engl J Med 1993; 328: 1759-69.
2. Alkatout I, Meinhold-Heerlein I, Keckstein J, Mettler L. Endometriosis: A concise practical guide to current diagnosis and treatment. J Turk Ger Gynecol Assoc 2018; 19: 173-5.

3. Alkatout I, Wedel T, Maass N. Combined treatment of endometriosis: radical yet gentle. Aktuelle Urol 2018; 49: 60-72.

4. Laganà AS, Vitale SG, Granese R, Palmara V, Ban Frangež $H$, Vrtačnik-Bokal E, et al. Clinical dynamics of Dienogest for the treatment of endometriosis: from bench to bedside. Expert Opin Drug Metab Toxicol 2017; 13: 593-6.

5. Fourquet J, Báez L, Figueroa M, Iriarte RI, Flores I. Quantification of the impact of endometriosis symptoms on health-related quality of life and work productivity. Fertil Steril 2011; 96: 107-12.

6. Hudelist G, Fritzer N, Thomas A, Niehues C, Oppelt P, Haas D, et al. Diagnostic delay for endometriosis in Austria and Germany: causes and possible consequences. Hum Reprod 2012; 27: 3412-6.

7. Ballard KD, Seaman HE, de Vries CS, Wright JT. Can symptomatology help in the diagnosis of endometriosis? Findings from a national case-control study--Part 1. BJOG 2008; 115: 1382-91.

8. Viganò P, Parazzini F, Somigliana E, Vercellini P. Endometriosis: epidemiology and aetiological factors. Best Pract Res Clin Obstet Gynaecol 2004; 18: 177-200.

9. Mathias SD, Kuppermann M, Liberman RF, Lipschutz RC, Steege JF. Chronic pelvic pain: prevalence, health-related quality of life, and economic correlates. Obstet Gynecol 1996; 87: 321-7.

10. Zondervan KT, Yudkin PL, Vessey MP, Jenkinson CP, Dawes MG, Barlow $\mathrm{DH}$, et al. The community prevalence of chronic pelvic pain in women and associated illness behaviour. Br J Gen Pract 2001; 51: 541-7.

11. Grace VM, Zondervan KT. Chronic pelvic pain in New Zealand: prevalence, pain severity, diagnoses and use of the health services. Aust N Z J Pub Health 2004; 28: 369-75.

12. Laganà $\mathrm{AS}$, Garzon $\mathrm{S}$, Götte $\mathrm{M}$, Viganò $\mathrm{P}$, Franchi $\mathrm{M}$, Ghezzi $\mathrm{F}$, et al. The pathogenesis of endometriosis: molecular and cell biology insights. Int J Mol Sci 2019; 20: 5615.

13. Laganà AS, Salmeri FM, Ban Frangež H, Ghezzi F, Vrtačnik-Bokal E, Granese R. Evaluation of M1 and M2 macrophages in ovarian endometriomas from women affected by endometriosis at different stages of the disease. Gynecol Endocrinol 2020; 36: 441-4. 
14. Filipchiuk C, Laganà AS, Beteli R, Ponce TG, Christofolini DM, Martins Trevisan C, et al. BIRC5/Survivin Expression as a Non-Invasive Biomarker of Endometriosis. Diagnostics (Basel) 2020; 10: 533.

15. Giudice LC, Kao LC. Endometriosis. Lancet 2004; 364: 1789-99.

16. Freytag D, Mettler L, Maass N, Günther V, Alkatout I. Uterine anomalies and endometriosis. Minerva Med 2020; 111: 33-49.

17. Ulrich U, Buchweitz O, Greb R, Keckstein J, von Leffern I, Oppelt P, et al; German and Austrian Societies for Obstetrics and Gynecology. National German Guideline (S2k): guideline for the diagnosis and treatment of endometriosis: long version - AWMF registry no. 015045. Geburtshilfe Frauenheilkd 2014; 74: 1104-18.

18. Dunselman GA, Vermeulen N, Becker C, Calhaz-Jorge C, D'Hooghe T, De Bie B, et al. European Society of Human Reproduction and Embryology. ESHRE guideline: management of women with endometriosis. Hum Reprod 2014; 29: 400-12.

19. Bourdel N, Alves J, Pickering G, Ramilo I, Roman H, Canis M. Systematic review of endometriosis pain assessment: how to choose a scale? Hum Reprod Update 2015; 21: 136-52.

20. Bazot M, Bharwani N, Huchon C, Kinkel K, Cunha TM, Guerra A, et al. European society of urogenital radiology (ESUR) guidelines: MR imaging of pelvic endometriosis. Eur Radiol 2017; 27: 2765-75.

21. Bazot M, Malzy P, Cortez A, Roseau G, Amouyal P, Daraï E. Accuracy of transvaginal sonography and endoscopic sonography in the diagnosis of dep infiltrating endometriosis. Ultrasound Obstet Gynecol 2007; 30: 994-1001.

22. Hudelist G, Ballard K, English J, Wright J, Banerjee S, Mastoroudes $\mathrm{H}$, et al. Transvaginal sonography vs. clinical examination in the preoperative diagnosis of deep infiltrating endometriosis. Ultrasound Obstet Gynecol 2011; 37: 480-7.

23. Raffaelli R, Garzon S, Baggio S, Genna M, Pomini P, Laganà AS, et al. Mesenteric vascular and nerve sparing surgery in laparoscopic segmental intestinal resection for deep infiltrating endometriosis. Eur J Obstet Gynecol Reprod Biol 2018; 231: 214-9.

24. Nawroth F, Rahimi G, Nawroth C, Foth D, Ludwig M, Schmidt T. Is there an association between septate uterus and endometriosis? Hum Reprod 2006; 21: 542-4.

25. LaMonica R, Pinto J, Luciano D, Lyapis A, Luciano A. Incidence of septate uterus in reproductive-aged women with and without endometriosis. J Minim Invasive Gynecol 2016; 23: 610-3.

26. Fedele L, Bianchi S, Di Nola G, Franchi D, Candiani GB. Endometriosis and nonobstructive müllerian anomalies. Obstet Gynecol 1992; 79: 515-7.

27. Uğur M, Turan C, Mungan T, Kuşçu E, Senöz S, Ağiş HT, et al. Endometriosis in association with müllerian anomalies. Gynecol Obstet Invest 1995; 40: 261-4.
28. Maniglio P, Ricciardi E, Laganà AS, Triolo O, Caserta D. Epigenetic modifications of primordial reproductive tract: A common etiologic pathway for Mayer-Rokitansky-Kuster-Hauser Syndrome and endometriosis? Med Hypotheses 2016; 90: 4-5.

29. Sofo V, Götte M, Laganà AS, Salmeri FM, Triolo O, Sturlese E, et al. Correlation between dioxin and endometriosis: An epigenetic route to unravel the pathogenesis of the disease. Arch Gynecol Obstet 2015; 292: 973-86.

30. Guerriero S, Condous G, van den Bosch T, Valentin L, Leone FP, Van Schoubroeck D, et al. Systematic approach to sonographic evaluation of the pelvis in women with suspected endometriosis, including terms, definitions and measurements: a consensus opinion from the International Deep Endometriosis Analysis (IDEA) group. Ultrasound Obstet Gynecol 2016; 48: 318-32.

31. Van den Bosch T, Dueholm M, Leone FP, Valentin L, Rasmussen CK, Votino A, et al. Terms, definitions and measurements to describe sonographic features of myometrium and uterine masses: a consensus opinion from the Morphological Uterus Sonographic Assessment (MUSA) group. Ultrasound Obstet Gynecol 2015; 46: 284-98.

32. Timmerman D, Valentin L, Bourne TH, Collins WP, Verrelst $\mathrm{H}$, Vergote I; International Ovarian Tumor Analysis (IOTA) Group. Terms, definitions and measurements to describe the sonographic features of adnexal tumors: a consensus opinion from the International Ovarian Tumor Analysis (IOTA) Group. Ultrasound Obstet Gynecol 2000; 16: 500-5.

33. Ghezzi F, Raio L, Cromi A, Duwe DG, Beretta P, Buttarelli M, et al. "Kissing ovaries": a sonographic sign of moderate to severe endometriosis. Fertil Steril 2005; 83: 143-7.

34. Savelli L, Manuzzi L, Pollastri P, Mabrouk M, Seracchioli R, Venturoli S. Diagnostic accuracy and potential limitations of transvaginal sonography for bladder endometriosis. Ultrasound Obstet Gynecol 2009; 34: 595-600.

35. Knabben L, Imboden S, Fellmann B, Nirgianakis K, Kuhn A, Mueller MD. Urinary tract endometriosis in patients with deep infiltrating endometriosis: prevalence, symptoms, management, and proposal for a new clinical classification. Fertil Steril 2015; 103: 147-52.

36. Alkatout I. Laparoscopic hysterectomy: total or subtotal? - Functional and didactic aspects. Minim Invasive Ther Allied Technol 2020; 3: $1-11$.

37. Dürr W. Transvaginale Sonographie in der Gynäkologie. De Gruyter. Berlin, Germany; 2014. 